\title{
Effects of vertebral number variations on carcass traits and genotyping of Vertnin candidate gene in Kazakh sheep
}

\author{
Zhifeng Zhang ${ }^{1,2,3}$, Yawei Sun ${ }^{3,4}$, Wei Du ${ }^{3,4}$, Sangang $\mathrm{He}^{3,4}$, Mingjun Liü ${ }^{3,4, *}$, and Changyan Tian ${ }^{1, *}$
}

* Corresponding Authors: Mingjun Liu Tel: +86-991-3075280, Fax: +86-991-3075280,

E-mail: mingjun_l@sina.com

Changyan Tian

Tel: +86-991-7885301, Fax: +86-991-7885320,

E-mail: tianchy@ms.xjb.ac.cn

'State Key Laboratory of Desert and Oasis Ecology, Xinjiang Institute of Ecology and Geography, Chinese Academy of Sciences, Urumqi, Xinjiang 830011, China

2 University of Chinese Academy of Sciences, Beijing 100049, China

${ }^{3}$ Institute of Animal Biotechnology, Xinjiang Academy of Animal Science, Urumqi, Xinjiang 830026, China ${ }^{4}$ Key Laboratory of Genetics, Breeding and

Reproduction of Grass-Feeding Animal, Ministry of Agriculture, Key Laboratory of Animal Biotechnology of Xinjiang, Urumqi, Xinjiang 830026, China

Submitted Dec 14, 2016; Revised Jan 20, 2017; Accepted Mar 21, 2017
Objective: The vertebral number is associated with body length and carcass traits, which represents an economically important trait in farm animals. The variation of vertebral number has been observed in a few mammalian species. However, the variation of vertebral number and quantitative trait loci in sheep breeds have not been well addressed.

Methods: In our investigation, the information including gender, age, carcass weight, carcass length and the number of thoracic and lumbar vertebrae from 624 China Kazakh sheep was collected. The effect of vertebral number variation on carcass weight and carcass length was estimated by general linear model. Further, the polymorphic sites of Vertnin (VRTN) gene were identified by sequencing, and the association of the genotype and vertebral number variation was analyzed by the one-way analysis of variance model.

Results: The variation of thoracolumbar vertebrae number in Kazakh sheep (18 to 20) was smaller than that in Texel sheep (17 to 21). The individuals with 19 thoracolumbar vertebrae (T13L6) were dominant in Kazakh sheep (79.2\%). The association study showed that the numbers of thoracolumbar vertebrae were positively correlated with the carcass length and carcass weight, statistically significant with carcass length. To investigate the association of thoracolumbar vertebrae number with VRTN gene, we genotyped the VRTN gene. A total of 9 polymorphic sites were detected and only a single nucleotide polymorphism (SNP) (rs426367238) was suggested to associate with thoracic vertebral number statistically.

Conclusion: The variation of thoracolumbar vertebrae number positively associated with the carcass length and carcass weight, especially with the carcass length. VRTN gene polymorphism of the SNP (rs426367238) with significant effect on thoracic vertebral number could be as a candidate marker to further evaluate its role in influence of thoracolumbar vertebral number.

Keywords: Thoracic Vertebral Number; Lumbar Vertebral Number; Carcass Length; Carcass Weight; Vertnin Gene; Sheep

\section{INTRODUCTION}

In mammals, the vertebrate spinal column comprises a series of repeating bones called vertebrae, including the cervical, thoracic, lumbar, sacral, and caudal vertebrae. The number of vertebrae is relatively conserved in most mammalian species [1], whereas the variation in thoracic, lumbar and thoracolumbar (the summation of thoracic and lumbar vertebrae) numbers has been observed in a number of mammalian species, such as pig [2], sheep [3], and human [4]. Furthermore, the extent of vertebral number variation presented great differences within breeds. For example, the range of thoracolumbar number variation in European commercial swine breeds ( $\mathrm{n}=21$ to 23 ) like Large White and Landrace was larger than that in Asian breeds ( $n=19$ to 20) [2]. Similarly the range of variation was observed between European ovine breeds ( $\mathrm{n}=17$ to 21 ) like Texel and Scottish Blackface and Chinese indigenous breeds $(n=19$ to 21) like Mongolia Sheep [3,5].

The number of thoracolumbar vertebrae is associated with body length and carcass traits, and 
represents an important economical trait in livestock, because one extra vertebra expands the carcass length (CL) up to $80 \mathrm{~mm}$ in pig [6]. It is more remarkable that the addition of one thoracic vertebra increases a pair of spareribs which are the most valuable part of the pig and sheep carcass in Chinese market. The quantitative trait loci (QTLs) for the number of vertebrae in pigs have been investigated by many researchers worldwide. Two QTLs which affect vertebral number were initially identified on Susscrofa chromosome 1 (SSC 1) and Susscrofa chromosome 7 (SSC7) [7]. Vertnin (VRTN) gene on SSC7 and nuclear receptor subfamily 6 , group A, member 1 (NR6A1) gene on SSC1 were proposed as a strong candidate for vertebral number $[8,9]$, which were also verified by genome wide association studies in pigs [10-13]. Subsequently, the most likely causal variant which is an insertion of a fragment in the promoter region of VRTN gene has been identified [10]. More recently, Zhang et al further found that the VRTN gene and NR6A1 gene independently influenced the thoracic vertebral number (TVN) and lumbar vertebral number (LVN), respectively [12]. However, QTL for vertebral number in sheep has not been documented and thus needs further investigation.

Kazakh sheep which dominates the sheep population in west Xinjiang of China is one of the most excellent indigenous breeds and is main meat source for Muslim minorities such as Kazakh, Uighur and Hui. The aim of this study was i) to investigate the extent of vertebral number variation in Kazakh sheep, ii) to evaluate the effect of vertebral number variation on carcass weight (CW) and CL, and iii) to detect mutations in ovine VRTN gene and analyze their association with vertebral number. Our work initially revealed the variation character of thoracolumbar vertebrae number, the association of thoracolumbar vertebrae number with carcass trait, and the correlation of VRTN genotype on thoracolumbar vertebrae number. It could be of significance to improve productivity of Kazakh sheep by gene or marker selection, and overall understand the causal factors affecting vertebral number.

\section{MATERIAL AND METHODS}

\section{Ethics statement}

All of the animal procedures were performed in strict accordance with the guidelines proposed by the China Council on Animal Care and the Ministry of Agriculture of the People's Republic of China.

\section{Animals and phenotype recording}

After slaughter, gender, age, CW, CL (from the basis of tail to the basis of the neck), TVN, LVN, and thoracolumbar vertebral number (TLVN) were collected in the abattoir in Yining City of Xinjiang, China, from November to December in 2014.The age which was estimated by inspection of the teeth at slaughter ranged from 1 to 6 years.

\section{DNA extraction and mutations detection}

DNA was extracted from ear tissue using the standard phenolchloroform method [14]. The quality and quantity of the DNA were measured with a NanoDrop 2000 (Thermo Fisher Scientific Inc., Wilmington, DE, USA). DNA was at the concentrations $>50$ $\mathrm{ng} / \mu \mathrm{L}$, total volume $>50 \mu \mathrm{L}$, and the ratio of light absorption (A260/280) between 1.8 and 2.0.

According to sheep VRTN gene sequence in GenBank (Accession number: NC_019464.1), two sets of polymerase chain reaction (PCR) primers (Table 1) were designed using the Oligo 6.0 software and were synthesized by Sangon Biotech (Shanghai) Co., Ltd. Shanghai, China.

Two PCR fragments which were produced by use of primers above harbored the complete VRTN gene and PCR amplifications were performed with EasyTaq PCR SuperMix (-dye) (Transgen Biotech Co. Ltd. Beijing, China) in accordance to manufacturer's instructions. The conditions for the PCR were as follows: $94^{\circ} \mathrm{C}$ for $5 \mathrm{~min} ; 30$ cycles of $94^{\circ} \mathrm{C}$ for $45 \mathrm{~s}, 59^{\circ} \mathrm{C}$ for $45 \mathrm{~s}$, and $72^{\circ} \mathrm{C}$ for $90 \mathrm{~s}$; followed by a further $5 \mathrm{~min}$ extension at $72^{\circ} \mathrm{C}$. All PCR products were bi-directionally sequenced with original PCR primers on the ABI-PRISM3730 sequencer at Sangon Biotech (Shanghai) Co., Ltd. The sequence alignment and detection of mutations were conducted using the MEGA 6.0 software and Chromas 2.5 software.

\section{Statistical analysis}

All statistical analyses were performed by SPSS 19.0 for Windows (SPSS Inc., Chicago, IL, USA). Univariate analysis of variance (general linear model, GLM) was applied to estimate the effect of vertebral number variation on $\mathrm{CW}$ and length. All data were presented as estimated marginal means (EMMEANS) \pm standard error [15]. The model was:

$$
\mathrm{Y}_{\mathrm{ijk}}=\mu+\mathrm{A}_{\mathrm{i}}+\mathrm{G}_{\mathrm{j}}+\mathrm{V}_{\mathrm{k}}+\mathrm{E}_{\mathrm{ijk}}
$$

Where $Y_{\mathrm{ijk}}$ was the phenotypic value of each trait (CW or $\mathrm{CL}$ ), with $\mu$ as general mean; $A_{i}=$ fixed effect of the ith age at traits

Table 1. The primers sequences

\begin{tabular}{|c|c|c|c|c|}
\hline Product & Primer sequence $\left(5^{\prime}-3^{\prime}\right)$ & $\mathrm{Chr}$ & Position (OAR 4.0) & Product size (bp) \\
\hline \multirow[t]{2}{*}{1} & Forward: AGTGTCATCCAGGTACCCGTTC & 7 & 82533260 & 1,478 \\
\hline & Reverse: GCGGGACAATGGCACCCTCA & 7 & 82534737 & \\
\hline 2 & Reverse: GCACCAAGCAGAAGTTATGACC & 7 & 82535889 & \\
\hline
\end{tabular}


recorded ( $i=1$ to 6$) ; G_{j}=$ fixed effect of $j$ th gender $(j=1$ or 2 , representing male or female, respectively); $V_{k}=$ fixed effect of vertebral number, was replaced by $\mathrm{T}_{\mathrm{k}}(\mathrm{k}=1,2$, or 3 , representing 12,13 , or 14 thoracic vertebrae, respectively), $\mathrm{L}_{\mathrm{K}}(\mathrm{k}=1$ or 2 , representing 5 or 6 lumbar vertebrae, respectively ), $\mathrm{P}_{\mathrm{k}}(\mathrm{k}=1,2$, or 3 , representing 18,19, or 20 thoracolumbar vertebrae, respectively), or $\mathrm{F}_{\mathrm{k}}(\mathrm{k}=1,2,3$, or 4 , representing T12L6 (12 thoracic and 6 lumbar vertebrae), T13L5 (13 thoracic and 5 lumbar vertebrae), T13L6 (13 thoracic and 6 lumbar vertebrae) or T14L6 (14 thoracic and 6 lumbar vertebrae, respectively), when the effect of each kind of vertebra trait (TVN, LVN, TLVN or vertebral formula) was assessed (one at a time). $\mathrm{E}_{\mathrm{ijk}}$ was the random residual effect.

The association between the mutations in VRTN gene and vertebral number was performed by one-way analysis of variance (ANOVA) analyses. The additive effect of allele was calculated with: (AA-BB)/2 (AA: mean phenotypic value of homozygous individuals, $\mathrm{BB}$ : mean phenotypic value of the other homozygous individuals).

\section{RESULTS AND DISCUSSION}

\section{The degree of vertebral number variation}

In present investigation, a total of 624 Chinese Kazakh sheep were sampled for phenotype data including gender, age, CW, CL, and the number of thoracic and lumbar vertebrae. The ratio of TLVN variation is presented in Figure 1. The variation range observed for TVN was 12 to $14, \mathrm{LVN}$ was 5 to 6 , and TLVN was 18 to 20. The range of TLVN variation (18 to 20) in China Kazakh sheep was smaller than that in Texel and Scottish Blackface sheep (17 to 21) based on previous reports [3]. The further analysis showed that the range of TVN variation in Kazakh sheep was the same as that in Texel sheep, but the range of LVN (5 to 6) is much smaller than that in Texel sheep (4 to 8). Remarkably, individuals with 7 lumbar vertebrae accounted for relatively larger proportion in Texel and Scottish Blackface sheep (35.4\% and 60.8\%, respectively) $[3,16]$, but those have not been found in Kazakh sheep.

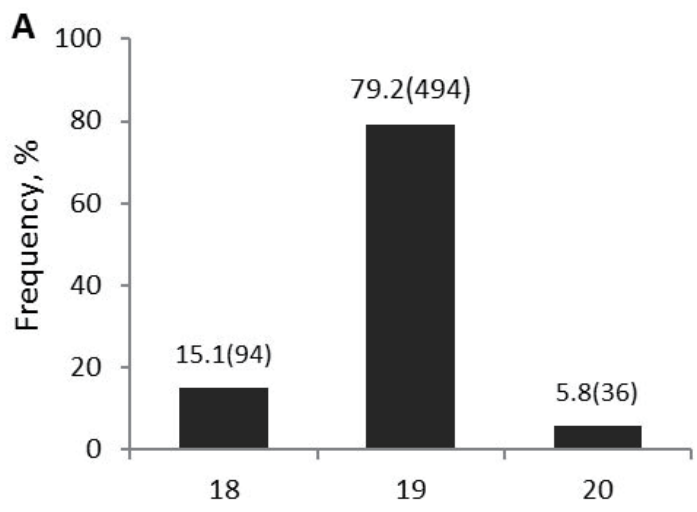

Thoracolumbar vertebral number
Frequency distributions revealed that the percentage of individuals with 19 thoracolumbar vertebrae was up to $79.2 \%$, obviously higher than that of the total samples with 18 or 20 thoracolumbar vertebrae (15.1\% and 5.8\%, respectively) (Figure 1a). The vertebral formulae consisted by T12L6, T13L5, T13L6, and T14L6, whereby T13L6 was the most common thoracolumbar vertebral composition (Figure 1b). In mammals, the number of thoracolumbar vertebrae was exclusively fixed at 19 (T13L6), so T13L6 was thought to be the primitive vertebrae form [1]. However, the changes in TLVN (from 21 to 23) were common in western modern pig breeds, such as Duroc, Landrace, and Large White, because these breeds have long been selectively bred for enlargement of body size and have presumably increased the number of vertebrae $[6,17]$. The percentages of animals possessing the extra vertebral counts were very low (Figure 1) in our investigation, which was reasonable, because Kazakh sheep are an old indigenous breed that was seldom subjected to artificial selection (cross-breeding). On the other hand, an investigation reported decades ago indicated that animals with more thoracolumbar vertebrae suffered from movement problems $[18,19]$. We speculated that the locomotion problem caused by extra vertebrae maybe was too slight to be observed when animals were grazing on flat pasture or in the breeding house. But Kazakh sheep originally lived in diverse terrain and animals with movement problem caused by more thoracolumbar vertebrae were eliminated by nature selection. This was the main second reason that the frequency of Kazakh sheep with more thoracolumbar was obviously lower than that of Texel and Scottish Blackface sheep breeds.

The effect of vertebral number variation on carcass weight and carcass length

Statistical analysis by GLM indicated that the TLVN affected CW and CL apparently (Table 2). The effect of TLVN on CL was more significant than on CW, and the effect on CL was highly significant $(\mathrm{p}<0.01)$.

The TVN and LVN independently were significantly corre-

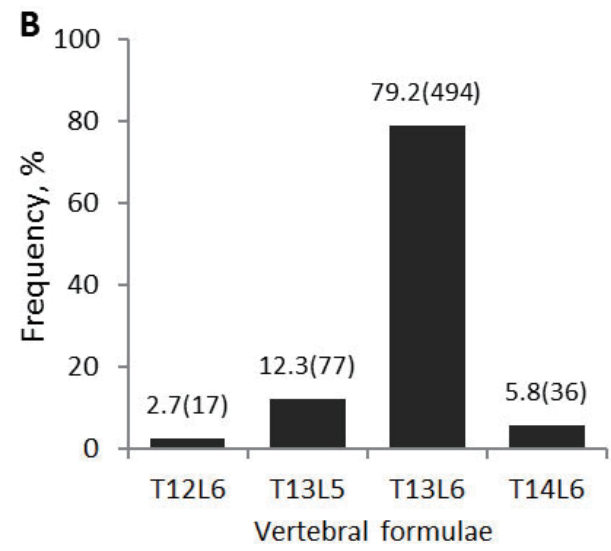

Figure 1. Variation and frequency of sheep thoracolumbar vertebral number and vertebral formulae. The number of individuals within each phenotype was given in brackets. T12L6, 12 thoracic and 6 lumbar vertebrae; T13L5, 13 thoracic and 5 lumbar vertebrae; T13L6, 13 thoracic and 6 lumbar vertebrae; T14L6, 14 thoracic and 6 lumbar vertebrae. 
Table 2. The effect of thoracolumbar vertebral number on carcass length and carcass weight

\begin{tabular}{lccc}
\hline TLVN & No. & CL $(\mathbf{c m})$ & CW $(\mathbf{k g})$ \\
\hline 18 & 94 & $71.06 \pm 0.83^{\mathrm{aA}}$ & $23.76 \pm 1.02^{\mathrm{a}}$ \\
19 & 494 & $72.28 \pm 0.73^{\mathrm{bAB}}$ & $24.26 \pm 0.89^{\mathrm{a}}$ \\
20 & 36 & $74.21 \pm 0.99^{\mathrm{CB}}$ & $24.63 \pm 1.21^{\mathrm{a}}$ \\
\hline
\end{tabular}

TLVN, thoracolumbar vertebral number; CL, carcass length; CW, carcass weight. Phenotypic values were shown in estimated marginal means \pm standard error.

Values with different superscript lowercase letters in the same column were significantly different $(p \leq 0.05)$

Values with different superscript capital letters in the same column were highly significantly different $(p \leq 0.01)$.

lated with CL (Supplementary Table S1, S2). Moreover, the effect of TVN on CL was larger than that of LVN. An extra thoracic vertebra increased the $\mathrm{CL}$ by around $17 \mathrm{~mm}$, and an extra lumbar vertebrae by $13 \mathrm{~mm}$ respectively. Notablly, the only variation in vertebral formulae with the same number of thoracolumbar vertebrae had little affect on CW and CL (Supplementary Table S3), however, the extra thoracic vertebrae not only apparently increased CL and longissimus muscle length which potentially positively associated with longissimus muscle weight, but also increased a pair of spareribs, hence it was a very important economical trait.

Furthermore, both extra thoracic and extra lumber vertebrae tended to increase CW, while it didn't reach to significant level statistically (Supplementary Table S1-S2), which was in line with the results in pigs [20]. We infered that CW was a complex quantity trait and was affected by multiple factors, especially by the fat weight [21]. Kazakh sheep has the character of typical fat-rumped tail. The rump weight is about $3.5 \mathrm{~kg}$ in average at maturity and is account for $16 \%$ of CW, which may have more influence on CW rather than on CL. So the effect of TLVN on CL was more significant than on carcass weight statistically.

In addition, previous studies showed that vertebra numbers were associated positively with leaner carcass, loin lengths and growth rate, and associated negatively with intramuscular fat content and fat deposition $[2,11,20,22]$. However, the association in sheep has not been addressed comprehensively.

\section{The polymorphisms of VRTN gene and their association} with vertebral number variation in Kazakh sheep

A total of 9 single nucleotide polymorphisms (SNPs) were detected in VRTN CDS, including 2 missense and 7 synonymous SNPs (Supplementary Table S4) by sequencing of 624 lambs. Of the 9 mutations, the SNP1259 (rs426367238) had significant effect on the number of thoracic vertebrae by ANOVA analyses (Table 3). Sheep with the $\mathrm{C} / \mathrm{C}$ genotype had significantly more TVN $(13.67 \pm 0.21)$ than those with the $\mathrm{C} / \mathrm{G}$ genotype $(13.22 \pm 0.06, \mathrm{p}=$ 0.022 ), and highly significantly more TVN than those with the $\mathrm{G} / \mathrm{G}$ genotype $(12.98 \pm 0.04, \mathrm{p}=0.004)$.

Subsequent analyses revealed that the SNP1259 (rs426367238)
Table 3. The effect of SNP1259 genotype on the number of thoracolumbar vertebrae

\begin{tabular}{lcccc}
\hline Genotype & No. & GF & TVN & LVN \\
\hline CC & 24 & 0.04 & $13.67 \pm 0.21^{\mathrm{aA}}$ & $5.67 \pm 0.21^{\mathrm{a}}$ \\
CG & 236 & 0.38 & $13.22 \pm 0.06^{\mathrm{bA}}$ & $5.58 \pm 0.07^{\mathrm{a}}$ \\
GG & 364 & 0.58 & $12.98 \pm 0.04^{\mathrm{CB}}$ & $5.56 \pm 0.05^{\mathrm{a}}$ \\
\hline
\end{tabular}

SNP, single nucleotide polymorphism; GF, genotypic frequency; TVN, thoracic vertebral number; LVN, lumbar vertebral number.

Phenotypic values were shown in estimated marginal means \pm standard error.

Values with different superscript lowercase letters in the same column were significantly different $(p \leq 0.05)$.

Values with different superscript capital letters in the same column were highly significantly different $(p \leq 0.01)$.

had an additive effect on the thoracic vertebrae number. The allele $\mathrm{C}$ with lower frequency $(0.23$, calculated from Table 2$)$ in our investigation was most presumably a causal genotype for increasing of vertebrae number. The effect of SNP1259 was an increase of approximate 0.4 thoracic vertebrae per allele, which was less than the additive effect of VRTN mutation in pigs ( 0.5 to 0.6 additional thoracic vertebrae per allele) [11]. Therefore, we speculated that there could be a number of other loci that affect TVN. On the other hand, none of the 9 SNPs had significant effect on the number of lumbar vertebrae. It inferred that the VRTN gene had strong association with thoracic vertebrae number variation, rather than with the number of lumbar vertebrae, which was consistent with previous result in pig $[10,12]$.

Our findings suggested that VRTN was the responsible gene for the variation of thoracic vertebrae number in sheep. VRTN was therefore likely to be an essential regulator for somitogenesis in the development of embryo in a wide range of vertebrate $[9,10]$. Nevertheless, the detailed underlying mechanism of VRTN in the development of vertebral formula remains largely unknown at present and needs further investigation.

\section{CONCLUSION}

The range of thoracolumbar vertebrae number variation was relatively smaller and there appeared to be a greater tendency to possess the primitive form with 19 thoracolumbar vertebrae (T13L6) in Chinese Kazakh sheep. This finding favored the assumption that Kazakh sheep was an old indigenous breed without artificial selection for large body size. The TLVN positively associated with the CL and carcass weight, especially with CL, which indicated that the vertebral number was very important economical trait in lamb production. VRTN gene polymorphism of SNP1259 with significant effect on TVN could be as a candidate marker to further evaluate its role in influence of TLVN.

\section{CONFLICT OF INTEREST}

We certify that there is no conflict of interest with any financial organization regarding the material discussed in the manuscript. 


\section{ACKNOWLEDGMENTS}

This study was financially supported by International Science \& Technology Cooperation Program of China (2014DFA30970).

\section{REFERENCES}

1.Narita Y, Kuratani S. Evolution of the vertebral formulae in mammals: a perspective on developmental constraints. J Exp Zool Part B 2005; 304:91-106.

2.Borchers N, Reinsch N, Kalm E. The number of ribs and vertebrae in a Piétran cross: variation, heritability and effects on performance traits. J Anim Breed Genet 2004;121:392-403.

3.Donaldson CL, Lambe NR, Maltin CA, Knott S, Bunger L. Betweenand within-breed variations of spine characteristics in sheep. J Anim Sci 2013;91:995-1004.

4.Ibrahim DA, Myung KS, Skaggs DL. Ten percent of patients with adolescent idiopathic scoliosis have variations in the number of thoracic or lumbar vertebrae. J Bone Joint Surg Am 2013;95:828-33.

5.Zhang L, Luo X, Siqinbilig, Zhang S. The lengths of thoracic and lumbar vertebrae and the performance of Mongolia sheep. J Inner Mongolia Inst Agric Anim Husb 1998;1998-03.

6.King J, Roberts R. Carcass length in the bacon pig: its association with vertebrae numbers and prediction from radiographs of the young pig. Anim prod 1960;2:59-65.

7.Mikawa S, Hayashi T, Nii M, et al. Two quantitative trait loci on Sus scrofa chromosomes 1 and 7 affecting the number of vertebrae. J Anim Sci 2005;83:2247-54.

8.Mikawa S, Morozumi T, Shimanuki S, et al. Fine mapping of a swine quantitative trait locus for number of vertebrae and analysis of an orphan nuclear receptor, germ cell nuclear factor (NR6A1). Genome Res 2007;17:586-93.

9.Mikawa S, Sato S, Nii M, et al. Identification of a second gene associated with variation in vertebral number in domestic pigs. BMC Genet 2011;12:5.

10. Fan Y, Xing Y, Zhang Z, et al. A further look at porcine chromosome 7 reveals VRTN variants associated with vertebral number in Chinese and Western pigs. PloSone 2013;8:e62534.

11. Rohrer GA, Nonneman DJ, Wiedmann RT, Schneider JF. A study of vertebra number in pigs confirms the association of vertnin and reveals additional QTL. BMC Genet 2015;16:129-38.

12. Zhang L-c, Liu X, Liang J, et al. Quantitative trait loci for the number of vertebrae on Sus scrofa chromosomes 1 and 7 independently influence the numbers of thoracic and lumbar vertebrae in pigs. J Int Agric 2015;14:2027-33.

13. Yang J, Huang L, Yang M, et al. Possible introgression of the VRTN mutation increasing vertebral number, carcass length and teat number from Chinese pigs into European pigs. Sci Rep 2016;6:19240.

14. Miller SA, Dykes DD, Polesky HF. A simple salting out procedure for extracting DNA from human nucleated cells. Nucleic Acids Res 1988;16:1215.

15. Searle SR, Speed FM, Milliken GA. Population marginal means in the linear model: an alternative to least squares means. AM STAT 1980;34: 216-21.

16. Lori DN, MacLeay JM, Turner AS. Variation in the lumbar spine of the mature ewe: a descriptive study. Vet Radiol Ultrasound 2005;46: 105-7.

17. Rubin CJ, Megens HJ, Martinez Barrio A, et al. Strong signatures of selection in the domestic pig genome. Proc Natl Acad Sci USA 2012; 109:19529-36.

18. Duckworth J, Holmes W. Selection for carcass length in Large White pigs. Anim Prod 1968;10:359-72.

19. Meyer H, Lindfeld A. Number and length of vertebrae in the improved German county-pig. Deut Tierarztl Woch 1969;76:448-53.

20. Nakano H, Sato S, Uemoto Y, et al. Effect of VRTN gene polymorphisms on Duroc pig production and carcass traits, and their genetic relationships. Anim Sci J 2015;86:125-31.

21. Safdarian M, Zamiri MJ, Hashemi M, Noorolahi H. Relationships of fat-tail dimensions with fat-tail weight and carcass characteristics at different slaughter weights of Torki-Ghashghaii sheep. Meat Sci 2008;80:686-9.

22. Hirose K, Mikawa S, Okumura N, et al. Association of swine vertnin (VRTN) gene with production traits in Duroc pigs improved using a closed nucleus breeding system. Anim Sci J 2013;84:213-21. 